\title{
Phage Therapy in COVID-19 Treatment
}

\author{
Yara Elahi ${ }^{1}$ and Ramin Mazaheri Nezhad Fard (ib) ${ }^{2,}$ \\ ${ }^{1}$ Department of Genetics, Faculty of Life Sciences, Islamic Azad University Tehran North Branch, Tehran, Iran \\ ${ }^{2}$ Department of Pathobiology, School of Public Health, Tehran University of Medical Sciences, Tehran, Iran \\ "Corresponding author: Department of Pathobiology, School of Public Health, Tehran University of Medical Sciences, Tehran, Iran. Email: raminmazaheri@gmail.com
}

Received 2021 July 20; Accepted 2021 November 04.

Keywords: Pandemy, Coronavirus, COVID-19, Antiviral Medication, Phage Therapy

\section{Dear editor,}

Since the global outbreak of coronavirus in 2019 , several studies have been carried out on this newly-emerged viral infection. However, no definitive cures have been reported for this deadly virus. Currently, the possible method to prevent further coronavirus spread and avoid its high mortality rate is vaccination. Despite efforts by governments and vaccine manufacturers to facilitate vaccination progress, it seems that further years are necessary to complete whole-nation vaccination schemes. Mass vaccination has become a challenge for governments because the number of highly effective vaccines is very limited. Moreover, vaccine sources are monopolized by developed countries. However, researchers have realized that even vaccination is not a perfect solution to prevent reinfections with the virus. Because coronaviruses are not likely to be completely eradicated due to their rapid evolution, alternative therapies seem necessary. Therefore, the use of bacteriophages (phages) as one of these alternative therapies might open up new horizons in front of medical specialists. Studies have verified that phages include antiviral and antifungal properties and their antibacterial properties (1). Phage therapy has recently been reported as an effective technique in suppressing the activation of nuclear factor kappa-light-chain-enhancer of activated B cells to build up immunity against viral pathogens. The upregulation of defensin 2 due to the phage therapy induces antiviral immunity (2). Based on recent studies, phages can be used for the production of artificial antibodies (Ab) in the primary stages of this viral infection (3). The antiviral potential of phages can be used to treat viral infections that affect the respiratory tract. Relatively, suggestions have been made for the production of phage-based vaccines (2). In conclusion, phage therapy can be an appro- priate solution for treating viral infections, including coronavirus disease 2019. However, further studies are needed to better understand phage-therapy mechanisms and verify their sufficient effectiveness in the treatment of urgent viral infections.

\section{Footnotes}

Authors' Contribution: Study concept and design: Y.E.; Analysis and interpretation of the data: R.MNF. and Y.E.; Drafting of the manuscript: Y.E.; Critical revision of the manuscript for important intellectual content: R.MNF; Statistical analysis: Y.E.

Conflict of Interests: The authors declare no conflict of interest.

Funding/Support: This study was not supported by any grant.

\section{References}

1. Gorski A, Bollyky PL, Przybylski M, Borysowski J, Miedzybrodzki R, Jonczyk-Matysiak E, et al. Perspectives of Phage Therapy in Non-bacterial Infections. Front Microbiol. 2018;9:3306. doi: 10.3389/fmicb.2018.03306. [PubMed: 30687285]. [PubMed Central: PMC6333649].

2. Singh AK, Gaur V, Kumar A. Role of Phage Therapy in COVID19 Infection: Future Prospects. IntechOpen. 2021. doi: 10.5772/intechopen.96788.

3. BalcioGlu BK, DenIzc IM, OztUrk HU, Y. Ucel F, Kaya F, Serhatli M, et al. SARS-CoV-2 neutralizing antibody development strategies. Turk J Biol. 2020;44(3):203-14. doi: 10.3906/biy-2005-91. [PubMed: 32595357]. [PubMed Central: PMC7314503]. 